\title{
Prevalence of the factor V Leiden mutation in hepatic and portal vein thrombosis
}

\author{
A E A Mahmoud, E Elias, N Beauchamp, J T Wilde
}

\begin{abstract}
Background-The factor V Leiden (FVL) mutation has been shown to be the most frequent cause of hereditary thrombophilia. The prevalence of the mutation in patients with Budd-Chiari syndrome (BCS) and portal vein thrombosis (PVT) has not been fully elucidated.

Aims-To investigate the association between the FVL mutation and BCS and PVT.

Patients-Thirty patients with BCS, 32 patients with PVT, and a control group of 54 patients with liver disorders and no history of thrombosis.

Methods-The factor $\mathrm{V}$ gene was analysed for the presence of the FVL mutation by a polymerase chain reaction (PCR) technique. The presence of the mutation was confirmed by DNA sequencing.

Results-Seven (23\%) patients with BCS, one $(3 \%)$ patient with PVT, and three $(6 \%)$ patients in the control group were identified as having the FVL mutation. Three of the BCS patients had coexisting hypercoagulable states. The prevalence of the FVL mutation was significantly higher in patients with BCS compared with patients with PVT and controls $(p<0.04)$. The FVL mutation was the second most common aetiology associated with BCS. Conclusion-The FVL mutation is an important factor in the pathogenesis of BCS and screening for the disorder must be included in the investigation of patients presenting with this condition. In contrast, the FVL mutation is not a major predisposing factor in the pathogenesis of PVT.
\end{abstract}

Liver \& Hepatobiliary

Unit

A E A Mahmoud

E Elias

Department of Haematology, Queen Elizabeth Hospital, Edgbaston, Birmingham B15 2TH $\mathrm{J} T$ Wilde

Department of Molecular Genetics, Royal Hallamshire Hospital, Glossop Road, Sheffield S10 2JF N Beauchamp

Correspondence to: Dr J T Wilde, Department of Haematology, Queen Elizabeth Hospital, Edgbaston, Birmingham B15 2TH.

Accepted for publication 20 February 1997

The association between hepatic vein thrombosis (Budd-Chiari syndrome, BCS) and myeloproliferative disorders (MPD) is well recognised $^{12}$ and the association with other hereditary and acquired thrombophilic states has also been reported..$^{3-6}$ Despite extensive investigation, however, no underlying cause can be identified in up to $30 \%$ of cases of BCS. Hypercoagulable states have also been implicated in the pathogenesis of portal vein thrombosis (PVT) although the association is not as strong as with BCS. ${ }^{7-10}$

The recently characterised factor $\mathrm{V}$ Leiden (FVL) mutation has been shown to be the most frequent cause of hereditary thrombophilia. ${ }^{11-13} \mathrm{We}$ and others have reported an association between BCS and FVL. ${ }^{14-15}$ To determine the strength of this association we have investigated the prevalence of FVL in patients with BCS and have sought to establish the relationship between the mutation and coexisting hereditary and acquired thrombotic conditions in the pathogenesis of this rare disorder. We have also investigated the prevalence of FVL in patients with PVT.

\section{Methods}

PATIENTS

Thirty patients with BCS (23 females and 7 males, median age 33 years, range 16-64) and 32 patients with PVT (13 females and 19 males, median age 47 years, range 19-68) were included in this study. Three of the patients with BCS were of Asian origin; the remaining patients with BCS and all patients with PVT were European Caucasians. Fifty four patients (29 females, 25 males, median age 43 years, range 17-69) chosen at random from those attending the liver unit with a range of hepatic disorders and no history of thrombotic disease were included as controls. All control patients were European Caucasians.

\section{LABORATORY ANALYSIS}

DNA was extracted using a DNA extraction kit (Puregene, Centra Systems Inc., USA) from peripheral blood samples obtained from the living patients (14 BCS and 20 PVT patients). DNA from deceased patients (16 BCS and 11 PVT patients) was obtained from paraffin embedded tissue obtained from previous liver biopsy specimens or frozen liver tissue stored routinely after liver transplantation.

Extracted DNA was analysed for the presence of the FVL mutation with the following oligonucleotide primers as described by Beauchamp et al ${ }^{16}:$ 5'-CATGAGAGACAT\section{CGCCTCTG, 5'-GACCTAACATGTTC-} TAGCCAGAAG. Amplification was achieved in a final volume of $100 \mu \mathrm{l}$ containing $30 \mathrm{pmol}$ of each primer, $200 \mu \mathrm{l}$ of each $\mathrm{dNTP}, 1.5 \mathrm{mM}$ $\mathrm{MgCl}_{2}, 2$ units of Taq DNA polymerase, and $2 \mu \mathrm{l}$ of extracted DNA. An initial denaturing step of seven minutes at $95^{\circ} \mathrm{C}$ was followed by 35 cycles at $94^{\circ} \mathrm{C}$ for one minute, $57^{\circ} \mathrm{C}$ for one minute, and $72^{\circ} \mathrm{C}$ for one minute with a final extension step of 10 minutes at $72^{\circ} \mathrm{C}$. The resultant 147 bp product was cleaved with MNl 1 (New England Biolabs) and subjected to polyacrylamide gel electrophoresis. The 
presence of the mutation was identified by observing the different patterns of cleavage after MN1 I digestion. In order to confirm our results all samples positive for the mutation and representative normal samples were cycle sequenced using Taq DNA polymerase and an automated DNA sequencer (Applied Biosystems Inc., UK) with fluorometric identification of bases.

All patients with BCS underwent a full thrombophilia screen including a full blood count, fibrinogen (Clauss assay), protein $\mathrm{C}$ activity (Immuno AG, Austria), protein $S$ antigen (Dako Antibodies, Denmark), antithrombin III activity (Immuno AG, Austria), and lupus anticoagulant screen.

\section{STATISTICAL ANALYSIS}

Fisher's exact test was used to compare the incidence of the mutation between the two groups; $p<0.05$ was considered significant.

\section{Results}

The underlying aetiologies of the patients with BCS are shown in Table $I$ and the liver pathologies in the patients with PVT and the control patients are summarised in Table II.

Seven $(23 \%)$ of the patients with BCS (six heterozygotes and one homozygote) were found to have the FVL mutation. Four of these patients (including the homozygote and one of the Asian patients) were female. None was taking the oral contraceptive pill or hormone replacement therapy at the time of presentation. One of the heterozygous female patients had a coexisting primary proliferative polycythaemia (PPP) and factor XII deficiency, and another had coexisting PPP and protein C deficiency. One of the heterozygous male patients had coexisting myelofibrosis. Only one (3\%) of the 32 patients with PVT was found

TABLE I Underlying aetiology in 30 patients with BCS

\begin{tabular}{lc}
\hline Underlying diagnosis & Number \\
\hline MPD & 7 \\
FVL & 4 \\
PCD & 2 \\
MPD+PCD & 1 \\
MPD+FVL & 1 \\
MPD+FVL+factor XII deficiency & 1 \\
MPD+PCD+FVL & 1 \\
Antithrombin III deficiency & 1 \\
Myelodysplasia & 1 \\
No underlying aetiology & 11 \\
\hline
\end{tabular}

MPD, myeloproliferative disorder; FVL, factor V Leiden mutation; PCD, protein $C$ deficiency.

TABLE II Liver pathologies in patients with PVT and controls

\begin{tabular}{llc}
\hline & $\begin{array}{l}P V T \\
(n=32)\end{array}$ & $\begin{array}{l}\text { Controls } \\
(n=54)\end{array}$ \\
\hline Alcoholic liver disease & 8 & 7 \\
Chronic active hepatitis & 7 & 6 \\
Primary sclerosing cholangitis & 5 & 7 \\
Primary biliary cirrhosis & 3 & 20 \\
Hepatitis B cirrhosis & 2 & 0 \\
Cryptogenic cirrhosis & 2 & 4 \\
$\alpha_{1}$-antitrypsin deficiency & 0 & 2 \\
Idiopathic PVT & 5 & 0 \\
Post liver transplantation for & 0 & 8 \\
fulminant hepatic failure & & \\
\hline
\end{tabular}

to be heterozygous for the FVL mutation and three heterozygotes $(6 \%)$ were identified in the control group. The prevalence of the FVL mutation was significantly higher in patients with BCS compared to those with PVT and control patients $(p<0 \cdot 04)$.

Two $(29 \%)$ of the patients with BCS and FVL (the homozygote and one of the heterozygous male patients) and six (26\%) of the patients with normal factor $\mathrm{V}$ died as a direct consequence of BCS soon after presentation. Neither of the patients with FVL had a coexisting hypercoagulable state whereas two of the patients with normal factor $\mathrm{V}$ had essential thrombocythaemia and a third had coexisting PPP and protein C deficiency. A further patient with normal factor $\mathrm{V}$ died four years after receiving an orthotopic liver transplant for BCS.

\section{Discussion}

The neutralisation of activated factors $\mathrm{V}$ and VIII by the activated protein C (APC)/protein $\mathrm{S}$ system is the most important natural anticoagulant mechanism preventing thrombus formation in the intact venous circulation or limiting clot propagation at sites of blood vessel injury.

The FVL defect is the most recently recognised hereditary thrombophilia state and has been shown to exhibit an autosomal dominant inheritance pattern. It is characterised by a point mutation at position 1691 in the factor $\mathrm{V}$ gene which results in the substitution of an arginine residue by glutamine at position 506 in the factor $\mathrm{V}$ molecule. ${ }^{12}$ The arginine 506-glycine 507 bond of the activated factor V molecule is the first site of cleavage by APC enabling protein $\mathrm{C}$ optimal access to the internal arginine 306-glycine 307 bond, cleavage of which results in neutralisation of factor $\mathrm{V}$ activity. APC is unable to cleave the glutamic acid 506-glycine 507 bond in the FVL molecule resulting in a ten times slower neutralisation of factor $\mathrm{V}$ activity compared with the action of APC on the normal molecule. This is believed to be the basis of the increased thrombotic tendency and the in vitro phenomenon of APC resistance observed in patients with the FVL mutation. The mutation is highly prevalent in individuals of European origin with a reported heterozygosity ranging from $2 \cdot 9 \%$ to $6 \% .^{12}{ }^{13}{ }^{16-18}$ Despite this high prevalence rate, heterozygosity for the mutation confers only a low thrombotic risk compared with individuals with a normal factor $\mathrm{V}$ molecule and many heterozygotes never experience thrombosis. ${ }^{19}$ The relative risk of thrombosis in heterozygotes has been estimated at 7.9 in one recent study. ${ }^{20}$

However, individuals with the mutation are more prone to thrombotic events in the presence of other recognised hereditary or acquired thrombotic risk factors such as protein $\mathrm{C}$ and protein $\mathrm{S}$ deficiency, and the oral contraceptive pill. ${ }^{20-23}$

The pathogenesis of BCS is poorly understood although clinical conditions well recognised as predisposing to thrombosis are often 
associated with its occurrence. ${ }^{14}$ In our series the FVL mutation was the second most common aetiology associated with BCS, being present in seven $(23 \%)$ of the 30 patients studied. Three patients, all heterozygotes, had additional underlying aetiologies which probably contributed to the thrombotic risk. The prevalence of the FVL mutation in the patients with BCS was significantly higher than that in the control group, highlighting the importance of the FVL mutation in the aetiology of BCS. The prevalence of the mutation in our chosen control group of patients with non-thrombotic liver disease and no history of thrombosis was $6 \%$, similar to that observed in normal European Caucasians. In any study of prevalence of the FVL mutation it is important that comparisons are made between groups of similar ethnic composition due to the notable worldwide variation in the prevalence of the mutation. The highest prevalence is found in Europeans whereas the prevalence is around $1 \%$ in individuals from the Indian subcontinent and the mutation does not appear to be present in individuals of Far Eastern origin. ${ }^{24}$ Although patient numbers are small the FVL mutation did not appear to confer an increased mortality risk in patients with BCS. Our findings highlight the importance of including FVL screening in the investigation of the aetiology of BCS.

PVT is a recognised complication of liver cirrhosis with a reported incidence of between $0.6 \%$ and $17 \%$. The pathogenesis of PVT in cirrhotic patients is uncertain, although it has been suggested that decreased portal blood flow and the presence of periportal lymphangitis and fibrosis in these patients promote the formation of thrombus. ${ }^{25}$ The contribution of coexisting thrombophilia states to the development of PVT in this setting has not been fully assessed. Both myeloproliferative disorders ${ }^{7}$ and hereditary and acquired thrombophilia states ${ }^{910}$ have been implicated as risk factors in the development of idiopathic PVT but in the majority of cases no underlying cause is identifiable. Idiopathic PVT has been associated with latent MPD that becomes apparent only years after the diagnosis of PVT. ${ }^{7}$ In our study of patients with PVT predominantly complicating cirrhosis, only one was found to have the FVL mutation. This would suggest that the FVL mutation is not an important predisposing risk factor in the pathogenesis of PVT complicating cirrhosis. As only five patients with idiopathic PVT were included in our study we are not able to comment on the relationship between the FVL mutation and the pathogenesis of this disorder. A larger series of patients with idiopathic PVT needs to be investigated in order to study this relationship in more detail.
1 Boughton BJ. Hepatic and portal vein thrombosis closely associated with chronic myeloproliferative disorders. BMf 1991; 302: 192-3.

2 Valla D, Casadevall N, Lacombe C, Varet B, Goldwasser E Franco D, et al. Primary myeloproliferative disorder and hepatic vein thrombosis. Ann Intern Med 1985; 103 329-34.

3 Mitchell MC, Boitnott JK, Kaufman S, Cameron JL, Maddrey WC. Budd-Chiari syndrome: etiology, diagnosis and management. Medicine 1982; 61: 199-218.

4 Mahmoud AEA, Mendoza A, Meshikhes AN, OlliffS, West R Neuberger J, et al. Clinical spectrum, investigations and treatment of Budd-Chiari syndrome. $Q 7$ Med 1996; 89: treatment

5 Pelletier S, Landi B, Piette JC, Ekert P, Coutellier A, Desmoulins $\mathrm{C}$, et al. Antiphospholipid syndrome as the second cause of non-tumorous Budd-Chiari syndrome. $\mathcal{f}$ Hepatol 1994; 21: 76-80.

6 Valla D, Le MG, Poynard T, Zucman N, Rueff B, Benhamou J-P. Risk of hepatic vein thrombosis in relation to recent use of oral contraceptives. Gastroenterology 1986 90: 807-11.

7 Valla D, Casadevall N, Huisse MG, Tulliez M, Grange JD, Muller $\mathrm{O}$, et al. Etiology of portal vein thrombosis in adults. A prospective evaluation of primary myeloproliferative A prospective evaluation of primary mye

8 Valla D, Denninger M-H, Delvigne J-M, Rueff B Benhamou J-P. Portal vein thrombosis with ruptured oesophageal varices as presenting manifestation of hereditary protein C deficiency. Gut 1988; 29: 856-9.

9 Sas G, Blasko G, Petr I, Griffin JH. A protein S deficien family with portal vein thrombosis. Thromb Haemost 1985 54: 724 .

10 Prat F, Ouzan D, Trecziak N, Trepo C. Portal and mesenteric thrombosis revealing constitutional protein $\mathrm{C}$ deficiency. Gut 1989; 30: 416 .

11 Dahlback B, Carlsson M, Svensson PJ. Familial thrombophilia due to a previously unrecognized mechanism characterized by poor anticoagulant response to activated protein C: prediction of a cofactor to activated protein C. protein C: prediction of a cofactor to activate

12 Bertina RM, Koeleman PC, Koster T, Rosendaal FR Dirven RJ, De Ronde $\mathrm{H}$, et al. Mutation in blood coagulation factor $\mathrm{V}$ associated with resistance to activated protein C. Nature 1994; 369: 64-7.

13 Svensson PJ, Dahlback B. Resistance to activated protein C as a basis for venous thrombosis. $N$ Engl $\mathcal{F}$ Med 1994; 330 517-22.

14 Mahmoud AEA, Wilde JT, Elias E. Budd-Chiari syndrome and factor V Leiden mutation. Lancet 1995; 345: 526 .

15 Denninger M-H, Beldjord K, Durand F, Denié C, Valla D, Guillin M-C. Budd-Chiari syndrome and factor V Leiden mutation. Lancet 1995; 345: 525-6.

16 Beauchamp NJ, Daly ME, Hampton KK, Cooper PC Preston FE, Peake IR. High prevalence of a mutation in Preston FE, Peake IR. High prevalence of a mutation in
the factor V gene within the UK population: relationship the factor $\mathrm{V}$ gene within the UK population: relationship to activated protein C resistance

17 Rosendaal FR, Koster T, Vaandenbrouke JP, Reitsma PH High risk of thrombosis in patients homozygous for factor $\mathrm{V}$ Leiden (activated protein C resistance). Blood 1995; 85 1504-8.

18 Ridker PM, Hennekens CH, Lindpaintner K, Stampfer MJ, Eisenberg PR, Miletich JP. Mutation in the gene coding for coagulation factor $\mathrm{V}$ and the risk of myocardial infarction, stroke and venous thrombosis in apparently healthy men. N Engl 7 Med 1995; 332: 912-17.

19 Zoller B, Svensson PJ, He X, Dahlback B. Identification of the same factor $V$ gene mutation in 47 out of 50 the same factor gene mutation in 47 out of 50 thrombosis-prone families with inherited resistance

20 Vandenbroucke JP, Koster T, Briet E, Reitsma PH Bertina RM, Rosendaal FR. Increased incidence of venous thrombosis in oral-contraceptive users who are carriers of factor V Leiden mutation. Lancet 1994; 344 1453-7.

21 Bertina RM, Reitsma PH, Rosendaal FR, Vandenbroucke JP. Resistance to activated protein $\mathrm{C}$ and factor $\mathrm{V}$ Leiden as risk factors for venous thrombosis. Thromb Haemost 1995 74: $449-53$

22 Koeleman BPC, Reitsma PH, Allaart CF, Bertina RM Activated protien $\mathrm{C}$ resistance as an additional risk factor for thrombosis in protein C deficient families. Blood 1994; 84: $1031-5$.

23 Zoller B, Berntsdotter A, Garcia de Frutos P, Dahlback B. Resistance to activated protein $C$ as an additional genetic Resistance to activated protein $C$ as an additional genetic
risk factor in hereditary deficiency of protein $S$. Blood risk factor in heredita

24 Rees DC, Cox M, Clegg JB. World distribution of factor V Leiden. Lancet 1995; 346: 1133-4.

25 Belli L, Sansalone CV, Aseni P, Romani F, Rondinara G Portal thrombosis in cirrhotics. A retrospective analysis. Ann Surg 1986; 203: 286-91. 